\title{
INHAL'T
}

E. BaUManN. J. S'JIWÄg ERGEN

Entwicklung eines Qualitätssicherungssystems für industriell hergestellte organische Düngestoffe . . .

M. Drews, R. Frank

Untersuchung zur Schadgrenze von Bor bei der Gewächshausgurke und Tomate

E. L'RBAN

Die Entnahme repräsentativer Fruchtstichproben aus Großkisten zur Beurteilung verschiedener Fruchtmerkmale des Apfels bei der Einlagerung

\section{W. Fiedler}

Untersnchungen zur technologischen Eignung von Erdbeeren für die maschinelle Ernte

I. Morphologische Merkmale und mechanische Belastbarkeit der Früchte

E. Baumann, F. Schneider

Die Wirkung von Siedlungsabfallkomposten unterschiedlicher Zusammensetzung auf den Ertrag von Feldgemüse

\section{СОДЕРЖА НИЕ}

Е. БАУМАН, Е. ШвәГЕРГЕН

Разработка системы по обеспечению качества органических удобренй, приготовленных промышленным методом .

М. ДРЕВС, Р. ФРАНК

Исследования предела вредного влияния бора у тепличного огурца и томата

E. УР

Взятие из контейнеров репрезентативных выборочных проб плодов для оценки различных показателей плодов в момент их складирования
B. ФИमJEР

Изучепие технологической пригодности земляники к машинной уборрке

I. Морфологические признаки и механическая предельно допустимая нагрузка плодов . . . . . . .

251 Е. Ба Уман, Ф. ШНАЙДЕР

Воздействие приготовленных из коммунальных отходов компостов различного состава на урожайность полевых овощей . . . . . . . .

\section{CONTENTS}

\section{F. BaUmann, J. SCHWÄgergen}

Development of a quality-ensuring system for organic manuring substances produced along industrial lines ...........

M. Drews, R. Frank

Investigation into the harmful boron content in greenhouse cucumber and tomato

E. URBAN

Representative fruit sampling from large boxes - Assessment of various fruit characters at the date of storage

\section{W. Fiedier}

Investigations on the technological suitability of strawberries for mechanized harvesting

I. Morphological characters and fruit response to mechanical load . . .

E. Baumane, F. Schneider

Effect of municipal waste composts of different composition on the yield of field regetables . . . . . . . . 295 